\title{
A Prototype of Industrial Waste Water Treatment Using Electrocoagulation
}

\author{
Phonnipha Boriboonsuksri ${ }^{1}$ and Natth Jun-krob ${ }^{2}$ \\ ${ }^{1}$ SAU- Safety Training centre, Safety Engineering Department, Southeast Asia University, Bangkok, Thailand \\ ${ }^{2}$ Electronics and Computer Engineering Department, Faculty of Engineering, Southeast Asia University, Bangkok, Thailand
}

\begin{abstract}
This paper proposes a construct of electrocoagulation waste water treatment system. The system consists of reactor tank, skimmer, cyclone tank and sediment tank. Waste water is feed into reactor tank. The electrochemical reaction is made emulsification to waste water. The contaminants are removed from waste water and can be divided to two kinds: light weight suspensions be floating up and another be sediment. The flocculants are skim out and the sediments are pumped out to sludge container. An electrical power which feed to electro-coagulation procedure is controlled by microcontroller. The user can be adjusted for suitable with waste water loaded. The input of waste water and output of sediments are controlled by PLC. The results, when operate with industrial waste water, can be treat by $30 \mathrm{~m}^{3} /$ day rates and the controlled parameter value: $\mathrm{pH}$, BOD, Oil \& Grease, COD, SS, TDS, and Ni are not exceed than the standard limit. The advantages of this system are consume small area and low power consumption.
\end{abstract}

\section{Introduction}

The electrocoagulation wastewater treatment is very interested in the present. Because the system requires less space and lower operating cost, when compared to other systems.[1] Many studies have tested the effectiveness of wastewater treatment by this method in different manners. But mostly confined only in laboratory scale.[2-5] Some work can be done commercially, but must be imported from abroad. That is expensive and lacks of specialists to operate the system. For this reason, the electrocoagulation waste water treatment system has not been used prevalent in Thailand. Our research team is interested in creating a prototype wastewater treatment by this method, which can be used practically in Thailand.

\section{The system design}

The proposed wastewater treatment process has three major components parts:

(1) The reactor tank (2) Skimmer and (3.) Cyclone and sedimentation tank. Each part-section will have to run the corresponding and appropriate to the flow rate of the treated water with details on Fig. 1. Which is consisting mainly parts of the following functions.

- Sludge pump: Used to pump the waste water from clarifier into the tank.

- Sump tank: Storage and discharge of waste water flowing into the reactor properly.

- Reactor tank: Serves to separate the contaminants in the wastewater into sludge.
- Sludge tank: Serves to storage sludge which formed by the reactor.

- Cyclone tank: This device served to stirring the heavy sediment settling quickly.

- Sediment tank: This tank served to precipitate the lightweight remains to be settling down.

- Power supply Unit: This device controls the electrical power supplied to the reactor. [6]

\subsection{Reactor tank}

The reaction tank is designed to support the power in series topology in order to reduce the power consumption of electronics devices of the power supply circuits. [6] An electrode, which is an aluminium sheet size $60 \times 120 \mathrm{~cm}$, 19 sheets were placed parallel to each other as a place far away as $56 \mathrm{~cm}$. The total reactions area of 13.68 square meters, as shown in Fig. 2 and the aerated sludge that occurs when the reaction shown in Fig. 3.

\subsection{Skimmer}

The light weight suspension is separated from waste water to float above level inside the reaction tank. The skimmer consists of sweep mechanism powered by an electric motor which is mounted buried beneath the lid of the reaction tank. All suspensions resulting from these treatments will be swept into a storage tank which is mounted on the side of the tank reactions on both sides. The skimming is controlled by a PLC, which skim automatically every 15 minutes. The skim sediments mechanism is shown in Fig. 4. 


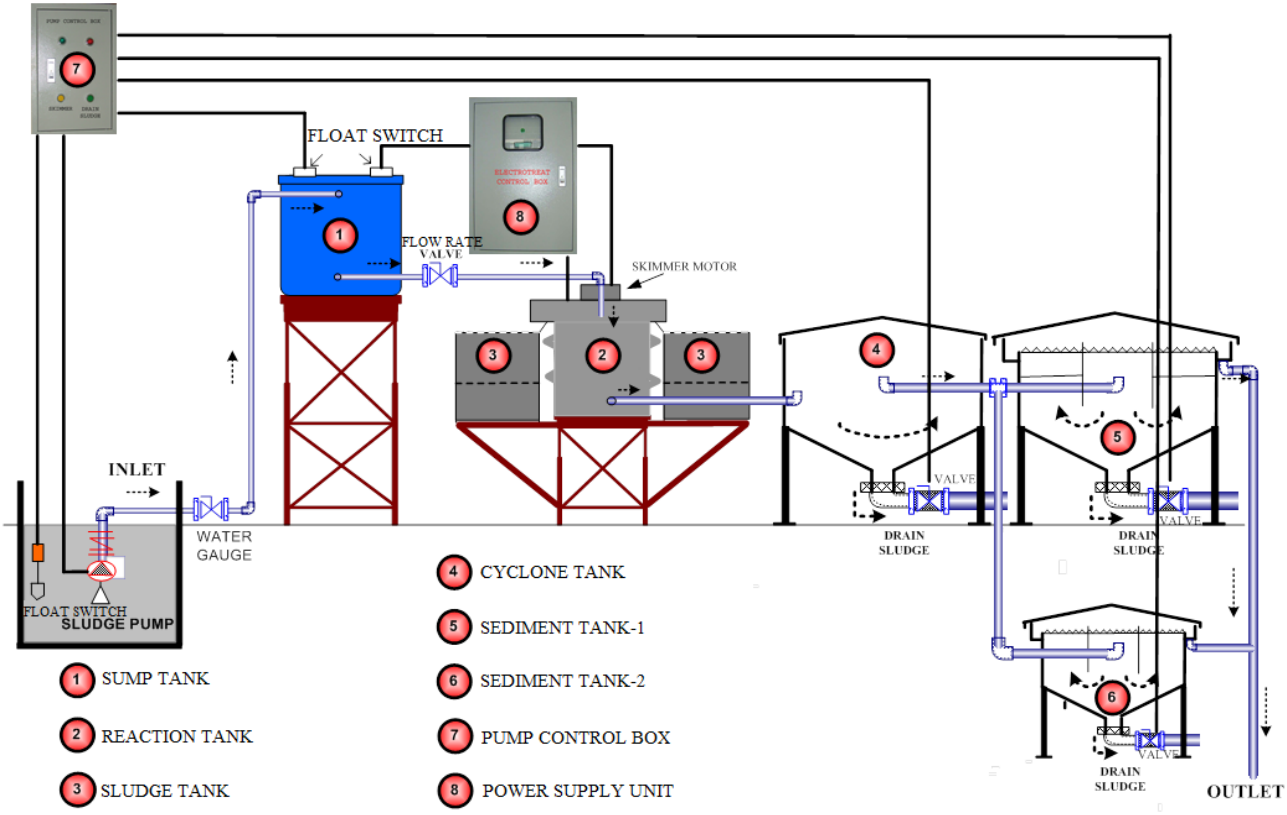

Figure 1. Diagram of the wastewater treatment plant operated with an electrocoagulation

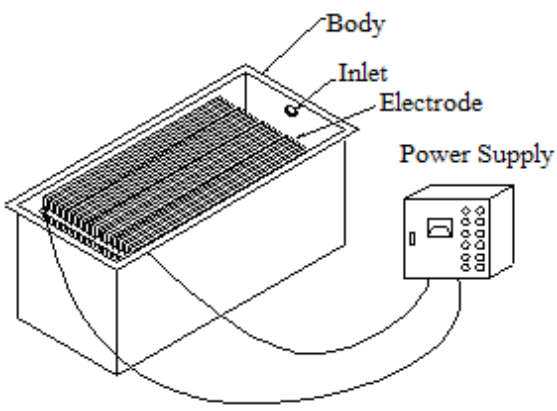

Figure 2. The structure of the reactor and its components

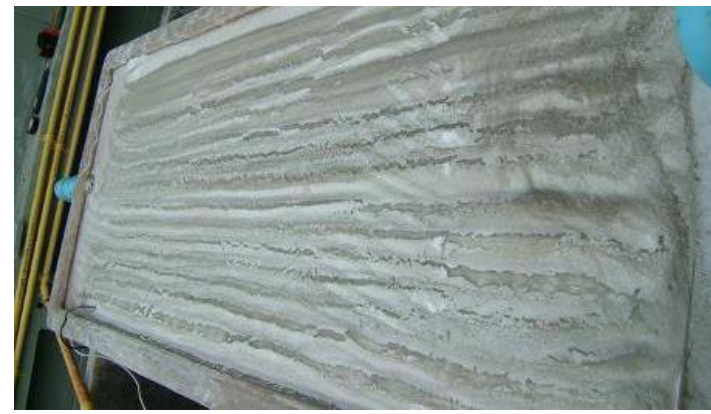

Figure 3. The rapid-settling flocs during test

\subsection{Coagulation}

The sediments caused by the extraction of water in the reaction tank have weighs not enough to precipitate. It requires some time to gather the sedimentary. In this design, the system will consist of two parts: a cyclone tank and sedimentation tank.

\subsubsection{Cyclone tank}

This tank causes sedimentation to weigh enough to precipitate shortly. Which according to the phenomenal movement behaviour of objects in the cyclone tank, as shown in Fig. 5.

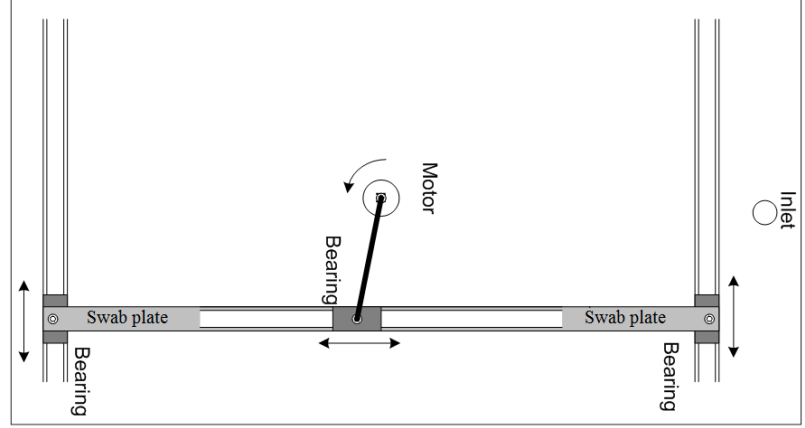

Figure 4. The structure of skimmer and its components

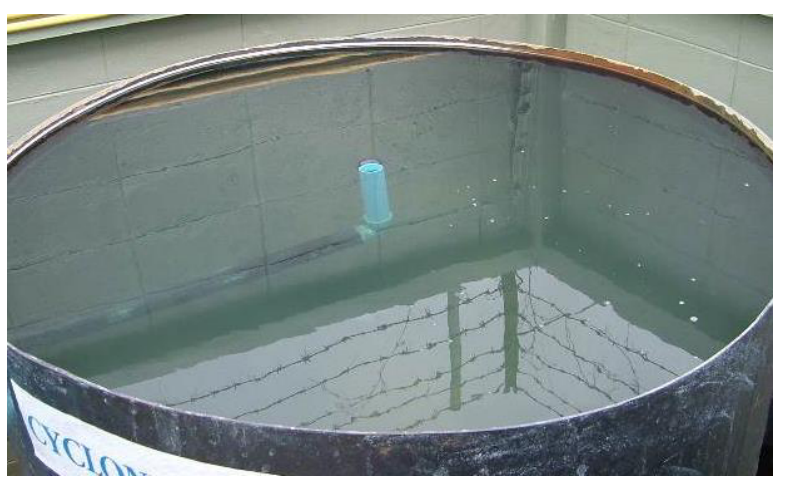

Figure 5. The cyclone tank

\subsubsection{Sedimentation tank}

This functions to taking sedimentation from the cyclone tank to fall to the bottom of the body. The top of this section constructs with a weir-overflow. And inside them containers with cross flow tube to increase precipitation efficiency as shown in Fig. 6.

\subsection{Control sludge management}

To store sedimentation, the mechanisms are controlled by a PLC controlled system, as shown in Fig. 7. This 
controls the sludge pump which submerged in the cyclone tank, sedimentation tank to carry out the sludge. And control motor skims fluctuate that floats on the surface of the reaction tank. Including controls "on/off" pumps to suction water into the treatment system. Moreover, the system also controls the "on/off" power supply to the reactor tank, which will shut down when there is no treatment wastewater into the system, as shown in Fig. 7.

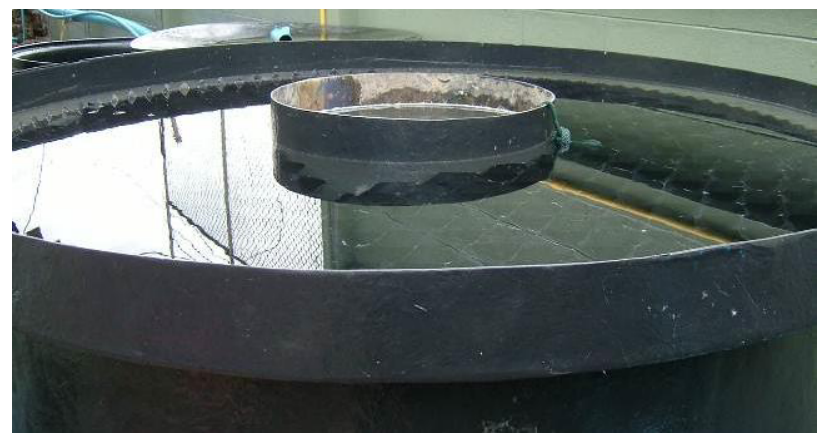

Figure 6. Sedimentation tank

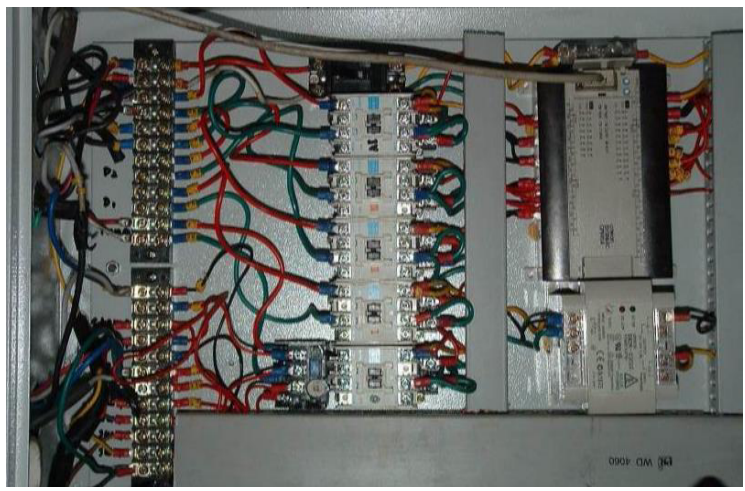

Figure 7. PLC Control sludge management system

\section{The process of systems}

Waste water is sucked from clarifier, which has a float switch for on/off the electric pump. In the absence of wastewater in clarifier, an electric pump and power supply will be turned off automatically. The wastewater is pumped into the sump tank to regulate the water pressure which flowing into the system with a fixed rate. The tank has two sets of float switch, the first functions to pumped water into the tank and control "on/off" pump to get the water level in the given point. Another switch functions to disable power supply if the water in the tank runs out. It sends a signal to stop supplying electricity to the system in order to save energy in the absence of wastewater treated. The wastewater will flow from sum tank into the reactor tank. . The flow rate of wastewater is controlled by a ball-valve. Waste water is treated in the reactor by the electrocoagulation function. These reactions reduce the stability and destroy the molecular bonds of the contaminants in the wastewater. As a result, mass spectrometry that can be separated contaminated wastewater, such as proteins, carbohydrates, fats, heavy metals and etc. from waste water. These contaminants are separated as sludge with a bubble floating up into the lighter sludge floating on the surface of the reactor. The reactor has a blade skim to skim floc-sludge to flow into sludge tank, which is placed on the side. The treated water will be delivered to a cyclone tank, which served heavy-sludge falling to the bottom of the cyclone tank rapidly. In the bottom of the tank will be structured as a cone. Its ending is connected to a suction pump to carry heavy sludge to the yard dried automatically controlled by the PLC. After that, the water will be sent to a sedimentation tank to the settling of sediment that slows down again. The sedimentation tank is structured as weir overflow and inside the tank installation cross flow tube to accelerate precipitation. The bottom of the tank installs a pump to carry sludge to the yard to dry, as well as cyclone tank. The water is delivered from the factory as standard for the industry. Fig. 8 shows the overall of a prototype wastewater treatment that have been designed.

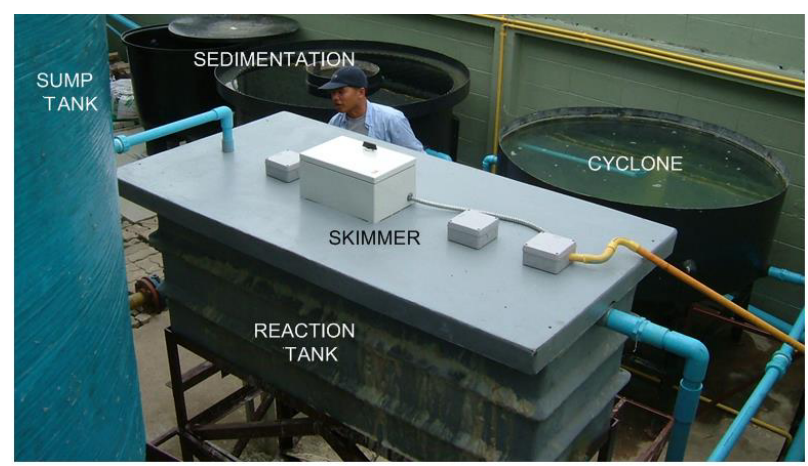

Figure 8 Prototype of industrial wastewater treatment with electrocoagulation

\section{The experiment results}

\subsection{Water quality after treatment}

A prototype has been installed to test in actual use of a S.C.I. Electric Manufacturer Co., ltd. This has the load of $500-\mathrm{BOD}_{5}$-wastewater from production of electrical wiring equipment parts and factory canteens with the rate of 30 cubic meters per day. The system operates with electric current supplying to the water treatment about 46 A. The treatment results showed in Table 1, which the water qualities are within the standard levels of discharged water from the factory that enforced by Thailand's Ministry of Industry.

Table 1. Results of water quality after treated

\begin{tabular}{|l|l|l|c|c|}
\hline \multicolumn{1}{|c|}{ Parameter } & Unit & \multicolumn{1}{|c|}{ Analysis Methode } & Standard Limit & Result \\
\hline \hline $\mathrm{pH}$ & & Electrometric Methode & $5.5-9.0$ & 8.16 \\
$\mathrm{BOD}$ & $\mathrm{mg} / \mathrm{L}$ & Axide Modification Methode & 20 & 11.00 \\
Oil and Grease & $\mathrm{mg} / \mathrm{L}$ & Partition Gravimetric Methode & 5 & 1.00 \\
$\mathrm{COD}$ & $\mathrm{mg} / \mathrm{L}$ & Closed Reflux, Colorimetric Method & 120 & 56.00 \\
$\mathrm{SS}$ & $\mathrm{mg} / \mathrm{L}$ & In-house Methode LT-01 & 50 & 5.60 \\
TDS & $\mathrm{mg} / \mathrm{L}$ & Dried at 180。C & 3000 & 599.00 \\
Nickel(Ni) & $\mathrm{mg} / \mathrm{L}$ & ICP & 1 & 0.13 \\
\hline
\end{tabular}

In long-term experiment, electrodes were adhesive with hydroxide and corrosion occurs. When operating over a long period of time, these barriers to the passage of an electric current. As a result, the efficiency of the water 
treatment is reduced. Fig. 9 shows the formation of hydroxide on the electrode system after use. Fig. 10 shows the erosion of aluminium electrodes in the reaction tank. Fig. 11 the nature of the sludge, which is a liquid cream and leave to dry soil, which can be planting crops.

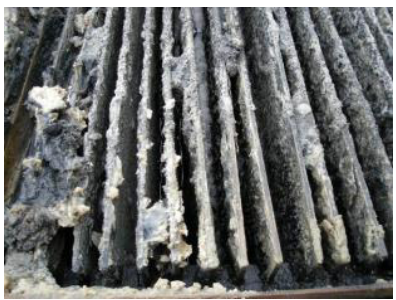

Figure 9. The hydroxide formation on the electrode

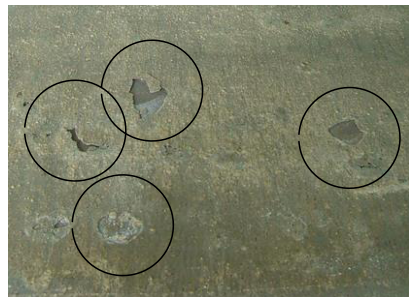

Figure 10. The erosion of electrodes occurs after use

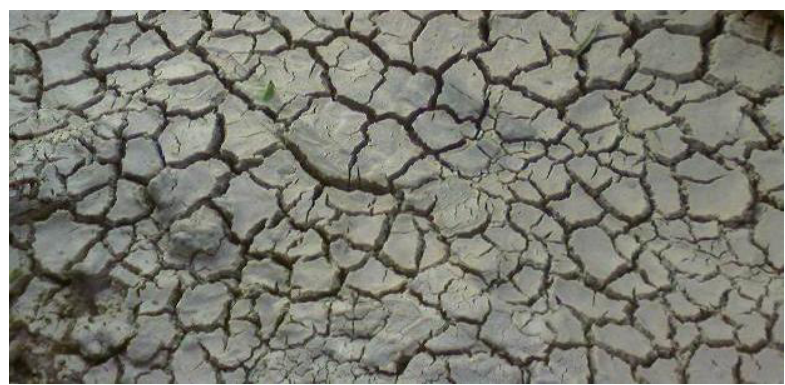

Figure 11. The nature of the sludge on leave until dry

\subsection{Energy consumption}

The system will consume electric energy in the total average of about 5 A. or about 792 units per month. And the cost of treatment was 2.64 baht per one cubic meter of $500-\mathrm{BOD}_{5}$-wastewater.

\subsection{Development of system performance}

We can see that, the main problem in the system is corrosion and the formation of a hydroxide formed on the electrode. Therefore, it is necessary to regularly to clean the electrode in a reaction tank to provide effective treatment of wastewater is not reduced. That is the burden of maintenance. A solution to these problems can be achieved by creating a mechanical abrasion electrode in a reaction tank, which will be developed in next-generation.

\subsection{A Mobile prototype for industrial testing service}

An academic service is an important mission of higher education institutions in Thailand. To exploring the extensive testing of waste water to the factory is essential for this work. The mobile unit prototypes for treated wastewater testing service have been designed as shown in Fig. 12. This system is design for compact and high mobility. Make it convenient to use for the service of wastewater treatment testing in the factory of industry in Thailand.

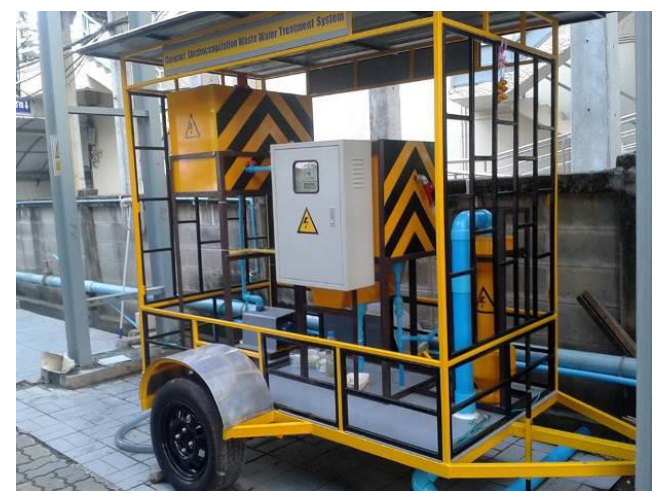

Figure 12. A mobile prototypes for Industrial testing service

\section{Conclusion}

The created Industrial prototype of the electrocoagulation wastewater treatment is capable up to 30 cubic meters of wastewater treatment per day. It consumables cost per unit for the treatment of about 2.64 baht per cubic meter. It used very little space, only 40 square meters. It has low operating costs compared with other systems. It has flexibility to customize with the volume of wastewater accrued per day. It is easy to use. It is a great solution to wastewater treatment for Thailand's industry in modern times. The problems encountered in operation is to maintenance for not to lose its effectiveness. That is needed to clean the electrode reactions in the tank frequently. And another problem is founded; the sludge that is produced from the electrocoagulation process is a cream that fine sediment. It needs a long time to dry and break up into soil. Therefore, it is necessary to have the location for them to dry sufficiently.

\section{Acknowledgement}

This research was funded by Southeast Asia university (ST003/2014) and S.C.I. Electric Manufacturer Co.,Ltd. We so thank you for supporting us in this opportunity.

\section{References}

1. S. Krisadawanich, S.E.A. Eng. J. 2, 11 (2006).

2. C. Barrera-Díaz, B. Frontana-Uribe, B. Bilyeu, Chem.105, 160 (2014)

3. V. Khandegar, A. K. Saroha, J. Env. Mgmt. 128, 949 (2013)

4. C. Ricordel, H. Djelal, J. Env.Chem. Eng. 2, 1551 (2014)

5. S. Zhao, G. Huang, G. Cheng, Y. Wang, H. Fu, Des.J.344, 454 ( 2014)

6. N. Jun-krob, S. Chean-arom, S. Sonantha, K. Kamonchot, Conf. ENETT-4 ${ }^{\text {th }}, 45$ (2008) 